\section{Protective Effect of Aged Vaccines on a Neurotropic Virus Infection in Mice}

A Number of clinical observations have established that recent immunization with diphtheria or whooping cough vaccines renders children more susceptible to poliomyelitis infection (see Hill and Knowelden ${ }^{\mathrm{I}}$ for references). A similar effect has been demonstrated in mice infected with the virus of mouse encephalomyelitis (GDVII strain) in experiments which are being reported fully elsewhere. During the course of the work, however, it was observed that the injection of vaccines which had been stored for several months no longer made the mice more susceptible to virus infection, but instead exerted a protective effect. It is felt that these findings, if confirmed, might have an important bearing on both clinical and biological problems.

The vaccines used were Diphtheria A.P.T., prepared by Burroughs Wellcome, and a pertussis vaccine prepared by the Medical Research Council. Both were stored at $0-3^{\circ} \mathrm{C}$. throughout the experiment. Serial tenfold dilutions of a standard suspension of virus-infected mouse brain (containing $3 \times 10^{8}$ intracerebral $L D 50$ 's per ml.) were injected into batches of three- to four-week old mice, $0.03 \mathrm{ml}$. into the calf muscle of each mouse; and from the numbers in each batch which succumbed, the 50 per cent lethal dilution was estimated by probit methods ${ }^{2}$. In the experimental series, a standard dose containing one part of each vaccine and four parts of distilled water was injected into the same leg muscles, usually $48 \mathrm{hr}$. after the injection of virus, and the 50 per cent lethal dilution again calculated. The altered susceptibility of the vaccine-treated series could then be expressed in terms of the 'mean probit difference'2 between the experimental and the control series.

The first supply of vaccines was obtained and tested in February 1951. The diphtheria vaccine had been prepared in October 1950, and was marked as fit for use until October 1952 ; the date of manufacture of the pertussis vaccine was not known.

When first tested, the combined vaccines increased approximately tenfold the susceptibility of mice to virus given $48 \mathrm{hr}$. previously. A month later, however, treatment with the same batch of vaccines produced little or no apparent increase in susceptibility. In September, the same vaccines were tested again, and were now found to decrease nearly tenfold the susceptibility of the mice to virus. This protective effect of the vaccine treatment was confirmed in a further experiment in November, and again in December. The probability of the apparent protective effect observed in these three experiments arising as a result of chance variation alone is less than one in a thousand.

A fresh supply of vaccines was obtained in Decem. ber 1951. The pertussis vaccine was from the same batch as before, while the Diphtheria A.P.T. was from a new lot, prepared in October 1951. The fresh vaecines again increased susceptibility when first tested (though to a lesser extent than the first batch), but by February showed a slight protective effect, and when last tested, in March 1952, increased the resistance of the mice more than tenfold, with again a very high degree of statistical significance $(P<0.001)$.

In the accompanying figure are plotted the mean probit differences between the control mice and the groups receiving injections of the combined vaccines
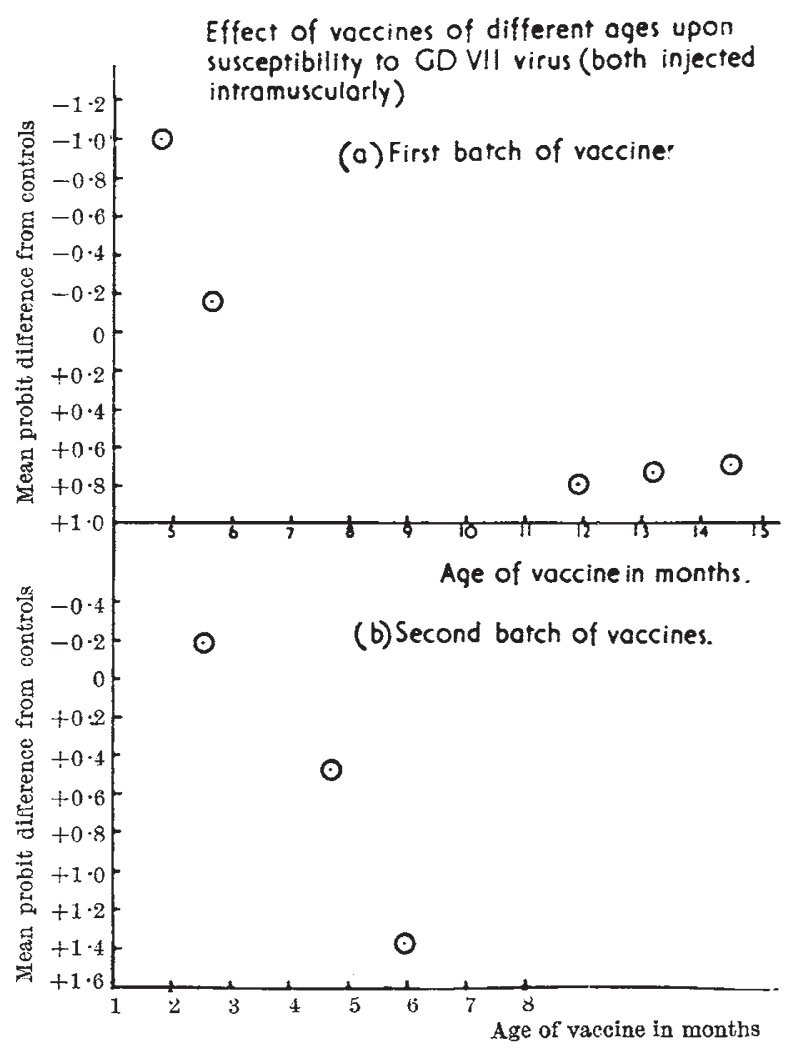

$48 \mathrm{hr}$. after the injection of virus. The initial increase in susceptibility, replaced in the course of a few months by an inarease in resistance, is apparent for both batches of vaccine. Since the effect does not appear to be related to the season of the year, one may conclude that the properties of one or both vaccines were altering with age.

No explanation of the protective effect of the aged vaccines is offered at this stage.

The expenses of this research were met by a grant from the Nuffield Foundation for virus work in this Department. My thanks are also due to the Medical Research Council for financial support, and to Dr. F. K. Sanders for advice and help.

AnNe Mclaren

Department of Zoology and Comparative Anatomy, Oxford. Jan. 12.

${ }^{1}$ Hill, A. B., and Knowelden, J., Brit. Med. J., ii, 1 (1950).

"Finney, D. J., "Probit Analysis"' (Cambridge, 1917).

\section{Agglutination of Red Cells by Cl. welchii}

THE hæmagglutination of sheep red cells by $C l$. septicum and the inhibition of the reaction by specific serum has already been described ${ }^{1}$.

Strains of $C l$. welchii types $A, B, C$ and $D$, respectively", grown on 5 per cent sheep blood agar for $48 \mathrm{hr}$., were suspended in normal saline solution and were treated with formalin to inactivate the hæmolysin. When two-fold dilutions were added to washed sheep red cells, incubated at $37^{\circ}$ for an hour, and then left overnight at room temperature, a sharp end-point in the agglutination of the red cells was obtained. $C l$. welch $i i$ types $B$ and $D$ were more active than types $A$ and $C$ (see table). Washed cultures 